\title{
Synthesis and Characterization of New Polymers Derivatives from Copoly (vinyl chloride - vinyl alcohol)
}

\author{
SUROR ABDULRAHMAN MAHDI* \\ Department of chemistry, college of science, university of Baghdad, \\ Jadiriya, Baghdad, Iraq . \\ *Corresponding author Email: surchem_82@yahoo.com
}

http://dx.doi.org/10.13005/ojc/330523

(Received: June 19, 2017; Accepted: August 01, 2017)

\begin{abstract}
In this work, new copolymer derivatives linked to poly (vinyl chloride- vinyl alcohol) (1-4) was synthesized via multisteps synthesis. Reaction of poly(vinylalcohol) (1) with adipoyl chloridein presence of benzene gave copoly(vinyloxy adipoyl chladipoyloride)(2) This is the first step. These cond step included the reaction of the prepared copolymer with ethanol to give copolymers (vinyloxy adipoyl ester)(3) which containing pendant esters group on polymeric chain. In the fourth step Oxindole subjected to Nucleophilic substitution reaction by vinyloxyadipoyl ester to give N-copolymer Oxindole (4) via Eschweiler-Clarke reaction. The prepared copolymers were identified by FT-IR and ${ }^{1} \mathrm{H}-\mathrm{NMR}$ spectra by studying the physical properties such as softening or melting points andsolubility.
\end{abstract}

Keyword: Polymers, Poly ( vinyl alcohol), Poly (adipoyl chloride), Oxindole.

\section{INTRODUCTION}

During the last three decades the role of polymers in biomedicine has seen significant growth. The unique physico-chemical properties offered by polymeric materials have been exploited in a variety of biomedical applications. However, an increasingly important aspect of the field of biomedical polymers is the recognition of the role of polymers as new and novel chemical entities for therapeutic application. For this purpose, the polymer may be intrinsically bioactive, or can be utilized as a carrier for site specific and sustained delivery of chemo- and biotherapeutic agents ${ }^{1}$. On the other hand PVA is an artificial polymer that has been used during the first half of the 20th century worldwide. It has been applied in the industrial, commercial, medical, and food sectors and has been used to produce many end products, such as lacquers, resins, surgical threads, and food packaging materials that are often in contact with food $^{2}$.Promoted by the above facts we report a facile synthesis of new polymer that may be valuable in design and biologically active ,starting from polymer (vinyl alcohol) to produce new copolymer containing hetercyclic. 


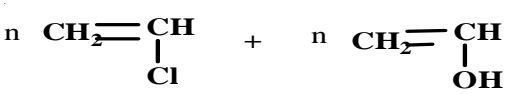

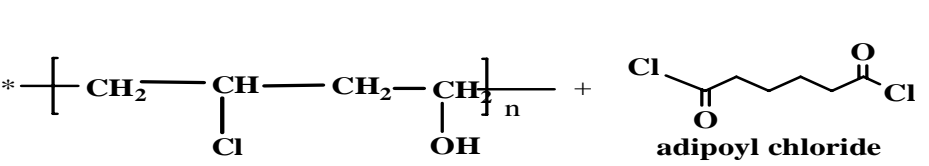

Copoly (vinyl chloride- vinyl alcohol)

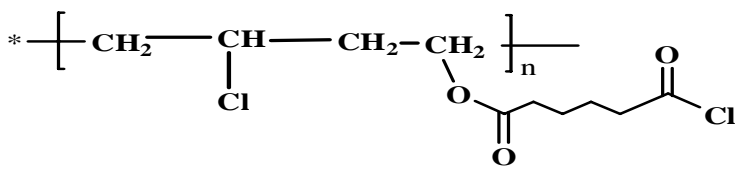

Copoly (vinyl chloride- vinyloxy adipoyl chloride)

Scheme. 1 : preparation of Copoly (vinyl chloride- vinyloxy adipoyl chloride).

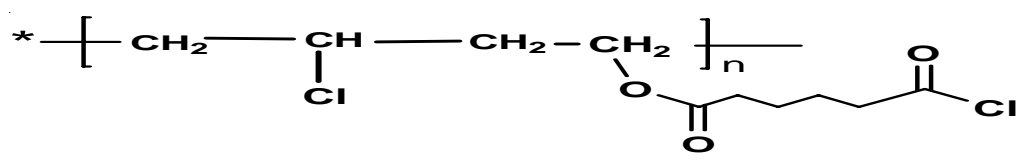

Copoly (vinyl chloride- vinyloxy adipoyl chloride)

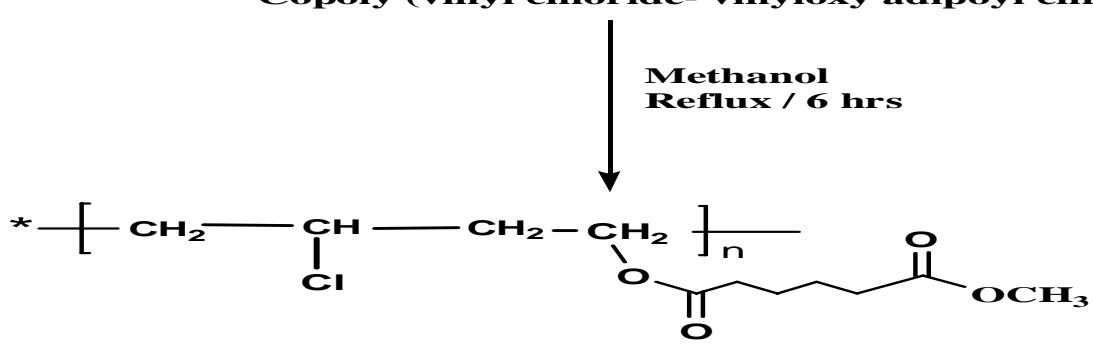

Copoly ( vinyl chloride- vinyloxy adipoyl methylate)

Scheme. 2 : Preparation of Copoly ( vinyl chloride- vinyloxy adipoyl methylate )<smiles>COC(=O)CCCCC(=O)OCCC(Cl)CC(C)(C)C</smiles><smiles>[Y]C(C)(C)CC(CCOC(=O)CCCCC(=O)OC)N1C(=O)Cc2ccccc21</smiles>

Scheme. 3 : Preparation of polymeric chain containing oxindole. 


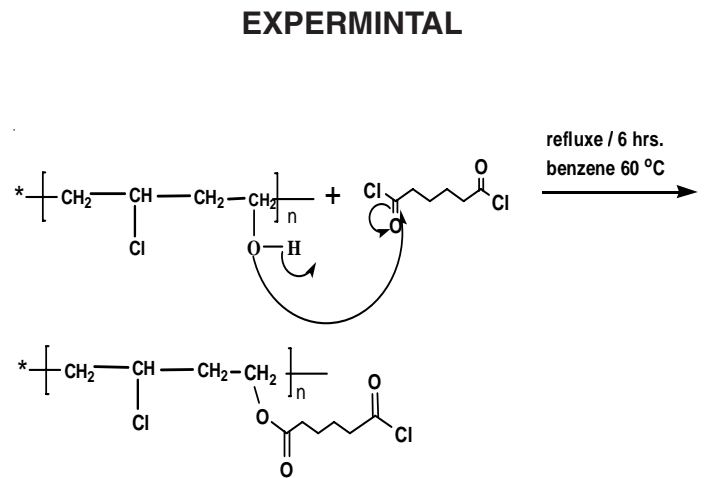

Scheme. 4 : The mechanism of compound (2).

Melting point were determined on Gallen kamp Melting point sapparatus(MFB-600),softening points were determined using Reichert the rmovar, $\mathrm{SP}, 1010.25,160$. Structures conformation of new prepared copolymer, were provedby FT-IR spectroscopy and other physical properties including so ftening points, melting points, solubility of copolymers were measured. All physical properties are usted in Table (1) , Fig. (2) H1-NMR and Fig. (3) -C13-NMR.

Preparation of poly (vinyloxy adipoyl chloride) (2).

Mixture $0.01 \mathrm{~mole}$ of poly (vinylalcohol) and $0.01 \mathrm{~mole}$ of adipoyl chloridein benzene used as asolvent were refluxed for $6 \mathrm{~h}$. sat $60^{\circ} \mathrm{C}$ to give new esterpoly(vinyloxy adipoylchloride)forming black precipitate ${ }^{3,4,5}$, purified by using THF. Conversition of yield $89 \%$. Softening point 189 $201^{\circ} \mathrm{C}$ and melting point $203-205^{\circ} \mathrm{C}$. All physical properties are showed in Table(1)

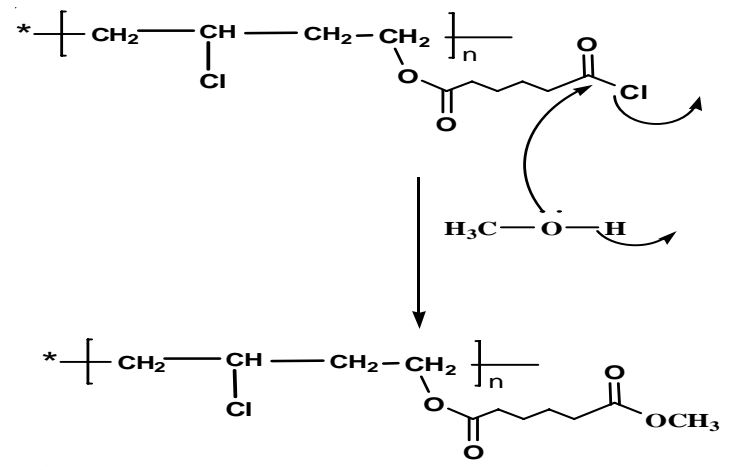

Scheme. 5 : The mechanism of compound (3).

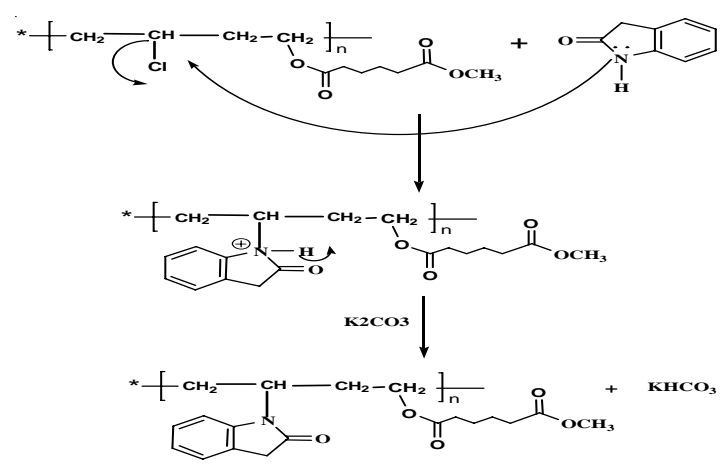

Scheme. 6 : The mechanism of compound (4).

Preparation of poly (vinyloxy adipoyl methylate) (3). Mixture 0.01 mole of poly (vinyloxyadipoylchloride) with 0.01 mole of ethanol were refluxed for $6 \mathrm{~h}$. sat $62^{\circ} \mathrm{C}$ to given ewester(grayprecipitate) $)^{6,7,8}$, which was purified by THF. Conversition of yield $84 \%$. Softening point 175 $190^{\circ} \mathrm{C}$ and melting point $185-189^{\circ} \mathrm{C}$ physical properties of new polymer are showed in table (1) FT-IR shown in Table(3).

Table. 1 : Physical properties for new poly (vinyl alcohol) and new ester derivatives.

\begin{tabular}{clccccc}
\hline Com. No & Polymer & time & Yield \% & Colour & Meltingpoint ${ }^{\circ} \mathbf{C}$ & $\begin{array}{c}\text { Softening } \\
\text { point }^{\circ} \mathbf{C}\end{array}$ \\
\hline 1 & poly(vinyl alcohol) & 6 hrs. & 78 & Pink. & $186-188$ & $161-171$ \\
2 & poly (vinyloxy adipoyl chloride) & 6 hrs. & 89 & Black & $203-205$ & $189-201$ \\
3 & poly (vinyloxy adipoyl ester) & 6 hrs. & 84 & gray & $185-189$ & $175-190$ \\
4 & Poly (ester oxindole) & 4 hrs. & 78 & Light brown & $168-171$ & $153-170$ \\
\hline
\end{tabular}


Preparation of poly (vinyloxy adipoyl methylate)bearingOxindole (4).

Oxindole (0.01) mole was treated with (0.01) mole of poly (vinyloxyadipoylmethylate) in the presense of potassium carbonate (0.5)g and

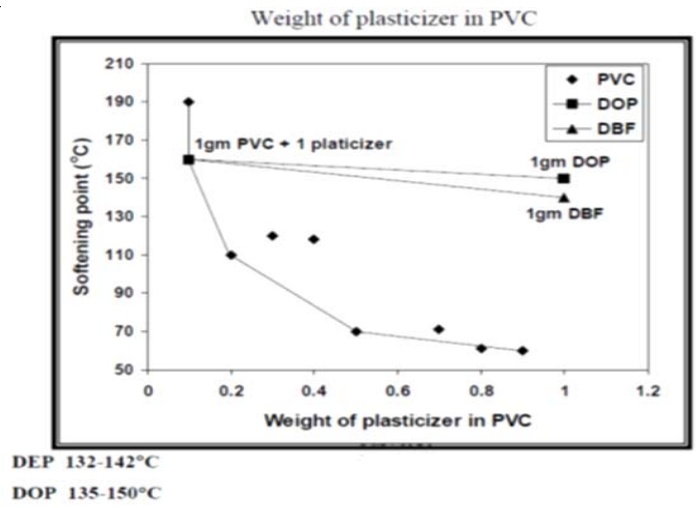

Fig. 1. Relationship curve between plasticizer and softening point.

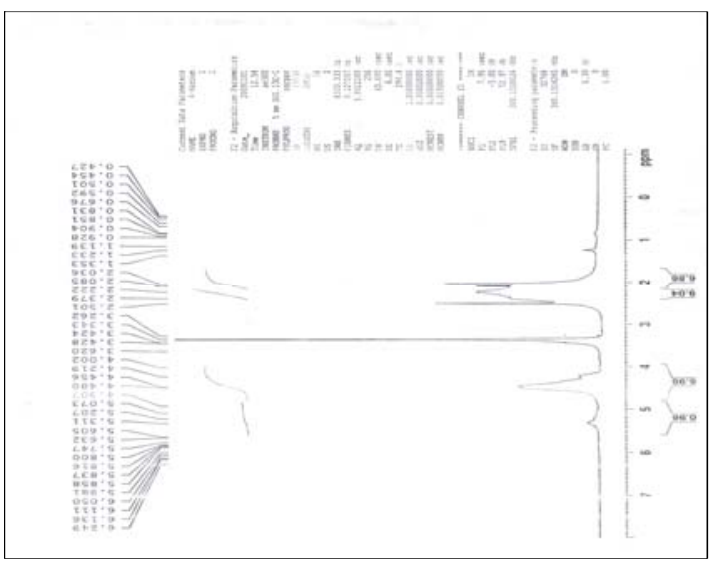

Fig. 2. $\mathrm{H}^{1}-\mathrm{NMR}$ of compound (3)
Dimethyl form amide as solvent, the mixture was refluxed for $4 \mathrm{~h}$. at $90^{\circ} \mathrm{C}$ then cooled, filtered and washed by hot water to yield light brown precipitate, Conversition of yield $78 \%$. Softening point $153-170^{\circ} \mathrm{C}$ and melting point $168-171^{\circ} \mathrm{C}$ physical properties of new polymer shown in table (1), FT-IR shown in Table(3).

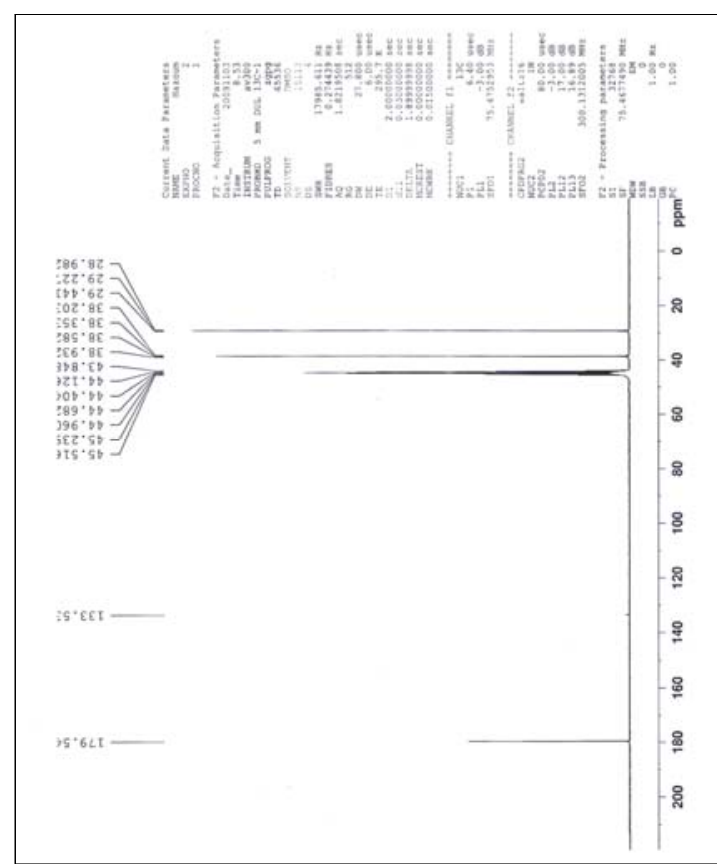

Fig. 3. $\mathrm{C}^{13}-\mathrm{NMR}$ of compound (3)

\section{Preparation of plasticizer}

Mixture of solid Igm of $\mathrm{PVC}^{9}$ with different weigh to fnewester bearing oxindoleco polymer ${ }^{4,5,6}$ (vinyloxyadipoylmethylateoxindole) $0.1 \mathrm{gm}$, 0.2 gm, 0.3 gm, 0.4 gm, 0.5 gm, 0.6 gm, 0.7 gm, 0.8

Table. 2 : Solubility of new polymer

\begin{tabular}{lcccccccc}
\hline NO. & Benzene & DMF & DMSO & THF & Water & CCI4 & Acetone EtOH \\
\hline 1 & V.S & V.S & V.S & V.S & P.S & P.S & V.S & V.S \\
2 & V.S & V.S & V.S & V.S & P.S & P.S & V.S & V.S \\
3 & V.S & V.S & V.S & V.S & P.S & P.S & V.S & V.S \\
4 & V.S & V.S & V.S & V.S & P.S & P.S & V.S & V.S \\
\hline
\end{tabular}

Table. 3 : FT-IR absorption spectra data (cm)-1 of new Polymer.

\begin{tabular}{cccccc}
\hline Comp. No. & $\mathrm{n}(\mathbf{C}-\mathrm{OH})$ & $\mathrm{n}(\mathbf{C}-\mathbf{O})$ & $\mathrm{n}(\mathbf{C}-\mathbf{C l})$ & $\mathrm{n}(\mathbf{C}-\mathrm{H})$ aliphatic & $\mathrm{n}(\mathbf{C}=\mathbf{O})$ \\
\hline 1 & $3250-3260$ & 1250 & - & 2990 & - \\
2 & - & 1280 & 617 & 2916 & 1697 \\
3 & - & 1242 & 694 & 2923 & 1735 \\
4 & - & - & - & 2914 & 1668 \\
\hline
\end{tabular}


Table. 4 : Relationshipbetweenweightof plasticizer in PVC and softening point.

\begin{tabular}{lcc}
\hline plasticizer & Weight\% & Softening point C \\
\hline poly & & \\
(vinyloxyadipoyl & $0.1 \mathrm{gm}+1 \mathrm{gm}$ pvc & $(187-215)$ \\
methylateoxindole) & $0.2 \mathrm{gm}+1 \mathrm{gm}$ pvc & $(113-138)$ \\
which is used with pvc & $0.3 \mathrm{gm}+1 \mathrm{gm}$ pvc & $(128-172)$ \\
& $0.4 \mathrm{gm}+1 \mathrm{gm}$ pvc & $(123-153)$ \\
& $0.5 \mathrm{gm}+1 \mathrm{gm}$ pvc & $(115-81)$ \\
& $0.6 \mathrm{gm}+1 \mathrm{gm}$ pvc & $(71-92)$ \\
& $0.7 \mathrm{gm}+1 \mathrm{gm}$ pvc & $(61-81)$ \\
& $0.8 \mathrm{gm}+1 \mathrm{gm}$ pvc & $(60-79)$ \\
& $0.9 \mathrm{gm}+1 \mathrm{gm}$ pvc & $(160-162)$ \\
\hline
\end{tabular}

$\mathrm{gm}, 0.9 \mathrm{gm}, 1 \mathrm{gm}$ of ester with $1 \mathrm{~g} \mathrm{~m}$ of PVC given ewphysical properties Softening pointof PVC with copoly (vinyloxyadipoylmethylateasshownintable (4)and relationship between weight of plasticizer in PVC ${ }^{10,11,12,13}$ with softening point shown in curve in Figure. (1) .

\section{RESULT AND DISCUSSION}

One of the suitable procedure for preparation of poly (vinylalcohol) from (vinylacetate $)^{1}$ by hydrolysis inacidic medium with acetoneunder refluxe.All physical properties listedin Table (1). The FT-IR spectrum show absorption bandat (3250- $3600)^{\mathrm{cm}-1}$ for $\mathrm{OH}$ group and at $680^{\mathrm{cm}-1}$ for $\mathrm{C}-\mathrm{Cl}$ and $1250^{\mathrm{cm}-1}$ for C-O alcoho I. The FT-IR spectra for poly(vinyloxy adipoyl chloride) ${ }^{2}$ showed absorption bandat $617^{\mathrm{cm}-1}$ for $\mathrm{C}-\mathrm{Cl}$ group, and at $1280^{\mathrm{cm}-1}$ for O-C-Oester group,and at $1697 \mathrm{~cm}-1$ for $\mathrm{C}=$ Oester group, and at $2916^{\mathrm{cm}-1}$ for C-H group. Mechansim of reaction is shown in scheme ${ }^{4,5,06}$.

The FT-IR spectra for new poly(vinyloxy adipoylmethylate ester) show absorption band ${ }^{14}$ at $1735^{\mathrm{cm}-1} \mathrm{C}=\mathrm{O}$ for ester group, and at $694^{\mathrm{cm}-1}$ for C$\mathrm{Cl}$ group, and at $2923^{\mathrm{cm}-1}$ for $\mathrm{C}-\mathrm{H}$ aliphatic group , and at $1242^{\mathrm{cm}-1}$ for O-C-O ester group . The FT-IR absorption spectra data ${ }^{\mathrm{cm}-1}$ of new polymers was shown in table (3):

\section{REFERENCE}

1. Jagur-Grodzinski.J., Erratum toBiomedical application of functional polymers, React. Funct. Polym. 1999., 39 , 99-138.

2. C.C.Demerlisand D.R. Schoneker, Review of the oral toxicity of polyvinyl alcohol (PVA), Food Chem. Toxicol., 2003 41, 319-326.

3. L.E. Coleman and Dunn, J.Org.Chem., 1959, 24,135 .

4. Rodriguez, F. Principle of polymer system 2nd.ed.McGraw-Hill Book company, 1983.

5. F.W. Billmeyer, Text book of polymer science"Wileyinterscience,NewYork. 1970.

6. T.M.Pyriadi, Practical polymer chemistry, University of Mousel press, ,Iraq. 1985

7. W.R. Roderick and Bhatia,P.L.,J.Org.chem., 1963, 28. 8.

8. C.E.Rehbery and C.H.Fisher, Polymer, Ind. Eng. chem.,1948, 40,1429.
9. J.R.Darbyand J.K. Sears,Plasticizers inencyclopedia of polymer science and Technology. 1969, 10,.228.

10. A.W.Campbell and P.F.Tryon, Ind. Eng. chem. 1953, 54,125.

11. R.F.Gould, plasticization and plasticizer processes, Advancein chemistry series NO.48, American chemical socity, Washington, D.C. 1965.

12. G.S.Misra, Introduction polymer chemistry EX-Director,Indianloc Research Institute Namkum,Ranchi, 1993.

13. A.K.Doolittle,"The Technology of solvents and plasticizer", New york, John wiley and sons, inc. 1954, 870.

14. D.H. williams and I.Fleming, "Spectroscopic method inorganic chemistry" Jon wiely and Sons New York, 1958. 